\title{
Research Paper: Body Image, Self-Esteem, and Psychological Problems Among Applicants and Non- applicants of Cosmetic Surgery
}

\author{
Aazam Heidarzadeh $^{1}$ (D), Parisa Shahmohammadipour ${ }^{1}$ (D), Mansooreh Azzizadeh Forouzi ${ }^{* *}$ (D), Mahlagha Dehghan ${ }^{2}$ (D), Zohreh Khorasani \\ 1. Department of Medical Surgical Nursing, School of Nursing \& Midwifery, Geriatric Care Research Center, Rafsanjan University of Medical Sciences, \\ Rafsanjan, Iran. \\ 2. Department of Medical Surgical Nursing, R. Nursing Research Center, Kerman University of Medical Sciences, Kerman, Iran \\ 3. School of Nursing and Midwifery, Isfahan University of Medical Sciences, Isfahan, Iran.
}

\begin{tabular}{|c|c|}
\hline $\begin{array}{l}\text { Use your device to scan } \\
\text { and read the article online }\end{array}$ & diteation: Heidarzadeh, A., Shahmohammadipour, P., Azzizadeh Forouzi, M., Dehghan, M., \& Khorasani, Z. (2019 \\
\hline pirpin: & $\begin{array}{l}\text { age, Self-Esteem, and Psychological Problems Among Applicants and Non-applicants of Cosmetic Surgery. Journal of Practice } \\
\text { in Clinical Psychology, 7(1), 33-42. http://dx.doi.org/10.32598/jpcp.7.1.33 }\end{array}$ \\
\hline 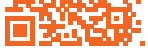 & doi'http://dx.doi.org/10.32598/jpcp.7.1.33 \\
\hline
\end{tabular}

\section{(c) (1) (9)}

Article info:

Received: 25 Jun 2018

Accepted: 14 Oct 2018

Available Online: 01 Jan 2019

\section{Keywords:}

Body image, Self-esteem, Psychological problems, Cosmetic surgery

\section{ABSTRACT}

Objective: The human beings' interest in beauty and improvement of their appearance might compel them to seek for cosmetic surgery. This study aimed to compare body image, selfesteem, and psychological problems between the applicants and non-applicants of cosmetic surgery in Iran.

Methods: This was a cross-sectional study. A total of 200 participants were selected for this study (including 100 applicants and 100 non-applicants of cosmetic surgery) via purposive sampling method. The questionnaires of body image, self-esteem, and psychological problems were used for data collection.

Results: The mean score of body image among non-applicants was higher than applicants of cosmetic surgery, but this difference was not statistically significant. In addition, there were no significant differences between the two groups regarding their self-esteem and psychological problems.

Conclusion: Cosmetic surgery is not necessarily associated with body image, self-esteem and psychological problems.

\section{* Corresponding Author:}

Mansooreh Azzizadeh Forouzi, MSc.

Address: Department of Medical Surgical Nursing, Faculty of Nursing \& Midwifery Razi, Nursing Research Center, Kerman University of Medical

Sciences, Kerman, Iran.

Tel: +98 (937) 1635739

E-mail:forozy@gmail.com 


\section{Highlights}

- Self-esteem, body image, and psychological problems were higher in applicants of cosmetic surgery.

- No significant differences between applicant and non-applicant with regard to self-esteem, body image, and psychological problems.

\section{Plain Language Summary}

This study was done to compare body image, self-esteem, and psychological problems between applicants and non-applicants of cosmetic surgery. We found that there is no difference in body image, self-esteem and psychological problems between the two groups. People who have less self-confidence have more chance of undergoing cosmetic surgery.

\section{Introduction}

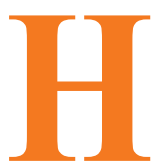

uman beings have long been interested in beauty (Khanjani, Babapour, \& Saba, 2012). Different cultures have always valued the attractive appearance of the people since the dawn of history. Based on the evidence, individuals with attractive appearances have benefited from this gift and solved their problems using their charm (Tousi, Barikbin, Arbabi, \& Saati, 2007). In addition, a beautiful face will improve and increase the individual's self-image and self-confidence. As a result, they usually perform their social activities at a more acceptable level (Khanjani et al., 2012).

In the $20^{\text {st }}$ century, especially in recent decades, new interpretations have been brought about beauty and it has been defined as a set of components such as fitness, cosmetics, clothing, attractiveness, and perfection (Von Soest, Kvalem, Roald, \& Skolleborg, 2009). Integration of beauty with industrial and medical advances has changed the attitudes toward beauty; therefore, beauty is not a mere congenital gift anymore but can be acquired (Khanjani et al., 2012). Nowadays, cosmetic surgery is one of the most common surgeries throughout the world and ever-increasing people use it (Dowling, Jackson, \& Honigman, 2013).

Invasive surgical procedures account for $18 \%$ of the total number of procedures, they comprise $63 \%$ of the total operating costs. Non-surgical, less expensive procedures have far surpassed surgical statistics with the introduction of Botox injections, facial fillers, and laser resurfacing. Altogether, it is estimated that these procedures have cost Americans over \$10 billion in 2011 (Riggs, 2012).
Although cosmetic surgery has been practicing in Iran since five decades ago, rapid changes in scientific and social issues have ranked Iran among the world's top 10 countries performing plastic surgery. Although no exact statistics are available in this regard, according to some reports, Iran has the first place among all countries in performing cosmetic surgeries (Mousavizadeh, Niazi Shahraki, Kalantar Hormozi, Fadaei Naeini, \& Nasri Lari, 2010).

In cosmetic surgery, the body appearance will change in the absence of any specific diseases, injuries, or congenital and inherited anomalies (Mohammadpanah, Yaghoobi, \& Yusefi, 2012). However, cosmetic surgery has changed into a glamorous mean of luxuriousness among different people resulting in unreal expectations of individuals and confounded realities about the nature of the operation (Farshidfar, Dastjerdi, \& Shahabizadeh, 2013). People have different objectives for cosmetic surgery such as beautifying their body appearance, having a more attractive face, improving apparent status, becoming successful in marriage, obtaining more self-confidence in social interactions, and satisfying the expectations of family and friends (Baniasadi, 2012).

One of the psychological aspects related to cosmetic surgery is body image (Jomeen \& Martin, 2005). Having a realistic and pleasant body image is necessary for enjoying from a healthy and fruitful social life and if people have a good feeling towards their physical body, they will likely to feel a positive body image (Hosseini, Ghasemi, Molayi Gonbadi, \& Rezayi, 2010). Nevertheless, dissatisfaction with body image will result in some consequences such as anxiety, social isolation, psychological disorders, and lowered self-esteem and self-concept (Zamani \& Fazilatpour, 2013). It seems that satisfaction with body image among young people requires 
satisfaction with five body factors: fitness and beautiful appearance, physical health, cleanness, healthy and beautiful skin, and ability to control weight (Khanjani et al., 2012; Pasha, Naaderi, \& Akbari, 2008).

Several studies assessed the effects of cosmetic surgery on human life and they all reported that after several years of follow-up, cosmetic surgery led to the improvement of body image and self-esteem (Zamani \& Fazilatpour, 2013). In addition, obese people were more interested in performing liposuction and they had lower body image than others (Frederick, Lever \& Peplau, 2007). According to Sarwer study, the participants reported better body image after cosmetic surgery (Sarwer et al., 2010).

In a study on rhinoplasty applicants, the participants with a low self-confidence but more interest in social interaction were more inclined to perform cosmetic surgeries (Baniasadi, 2012). In a study by Dowling et al. (2013), findings revealed high rates of postoperative satisfaction and significant improvements in overall dimensions of body image and mental health (anxiety, depression, and dysmorphic concerns), except for self-esteem (Dowling et al., 2013). Klassen, Jenkinson, Fitzpatrick and Goodacre (1996). in their study reported that all the patients demonstrated statistically significant improvements in their quality of life and self-esteem; however, only breast reduction patients reported significant improvements in their mental health after cosmetic surgery (Klassen et al., 1996).

Previous studies indicate that cosmetic surgery can contribute to psychological changes such as satisfaction with body image and self-esteem that might persuade the individuals toward cosmetic surgeries. However, the results of the studies were different and controversial. Therefore, this study aimed to compare body image, self-esteem and psychological problems between applicants and non-applicants for cosmetic surgery in Rafsanjan City, Iran.

\section{Methods}

This was a cross-sectional study to compare body image, self-confidence, and psychological problems between applicants and non-applicants of cosmetic surgeries in the two hospitals of Rafsanjan City, Iran.

The following formula was used to calculate the sample size. A total of 200 individuals were chosen to participate in the study by purposive sampling method that 100 of them were applicants for cosmetic surgery and 100 were non-applicants.

$$
n=\frac{\left(z_{1-\frac{a}{2}}+z_{1-\beta}\right) 2\left(\delta^{2}{ }_{1}+\delta^{2}{ }_{1}\right)}{\left(\mu_{1}-\mu_{2}\right)^{2}}
$$

A four-part questionnaire was used to collect the data, including 1. Demographic characteristics; 2. Body image; 3. Self-confidence; and 4. Psychological problems.

Demographic characteristics of the questionnaire included items related to personal characteristics of the participants such as age, gender, marital status, job, monthly income, type of surgery, date of surgery, and post-operation satisfaction. Multidimensional body-self relations questionnaire was designed by Rosenberg in 1965. It contains 46 items and 6 subscales, including 1. Evaluation of apparent status (7 items); 2. Tendency to appearance (12 items); 3. Evaluation of fitness (3 items); 4. Tendency to fitness (13 items); 5. Preoccupation with overweight or mental weight (2 items); and 6. Satisfaction with body areas ( 9 items). The scale score varies from 46 to 230 .

Kkeli and Argyrides (2013) studied the validity and reliability of the questionnaire. The internal consistencies of the subscales ranged from 0.76 to 0.86 . The test-retest reliabilities ranged from 0.75 to 0.93 . Also in Iran, Hosseini et al. (2010) studied the validity and reliability of the questionnaire and found its internal consistency coefficients from 0.80 to 0.92 for its different subscales

Rosenberg self-esteem questionnaire was designed by Rosenberg in 1965 in order to evaluate self-esteem. It has ten items with a 4-point Likert scale scoring (from "completely agree" to "completely disagree"). In this scale, five items $(2,5,6,8$, and 9) were inversely scored and its total score ranges from 10 to 40 . Higher scores indicate higher self-esteem. Piyavhatkul et al. (2011) studied the validity and reliability of the questionnaire and its Cronbach $\alpha$ for the Rosenberg self-esteem scale (Thai version) was 0.849 . Also, the Pearson correlation between this questionnaire and the self-esteem visual analog scale was 0.618 ( $\mathrm{P}=0.01)$. In Iran, Ahmadi and Poorsharifi (2013) studied the validity and reliability of the questionnaire and its Cronbach $\alpha$ coefficient was found as 0.85 .

Hopkins symptoms checklist 5-item questionnaire has four choices (from "not at all" to "very much"). The mean score for each item was calculated and higher scores indicate more psychological problems. Because this scale was used for the first time, the validity and reliability of the scales were rechecked in the Iranian context (backwardforward). Ten faculty members of Kerman University of 
Medical Sciences reviewed the content of the scale and agreed upon the appropriateness of the contents.

To reassess the reliability of the translated scale, a pilot study was done on applicants of cosmetic surgery and then the alpha coefficient value of the instrument internal consistency was computed 0.92 so the translated scale presented acceptable reliability and validity. The validity and reliability of the questionnaire were evaluated by Kvalevaag who reported its internal correlation coefficient as 0.92 (Kvalevaag et al., 2013).

In the present study, the target population was all the cosmetic surgery applicants (who referred to Rafsanjan hospitals) and their relatives. The inclusion criteria were being definitely the candidates for cosmetic surgery within the next 15 days, lacking any medical cause for cosmetic surgery, and undergoing cosmetic surgery in an operating room and not at an outpatient clinic (Klassen et al., 1996). The exclusion criteria were having a history of cosmetic surgery for the applicants and tendency toward cosmetic surgery in future for nonapplicants (Khanjani et al., 2012). Non-applicants were relatives of the applicants. A self-report questionnaire was distributed to subjects to complete it. Sampling was conducted from April 2013 to September 2013.

The obtained data were analyzed in SPSS version 18 . The participants' characteristics were described by descriptive statistics (frequency, percentage, mean and standard deviation). As the data lacked the normal distribution, the Mann-Whitney U test was used to compare body image, self-confidence, and psychological problems between cosmetic surgery applicants and non-applicants. Univariate and multivariate logistic regression were used to determine the relationship between socio-demographic characteristics and being an applicant for cosmetic surgery. The significance level was considered at 0.05 .

\section{Results}

\section{Socio-demographic characteristics}

Totally, 200 citizens of Rafsanjan participated in the study. Twenty subjects refused to continue the study, therefore the response rate was $90.9 \%$. The Mean \pm SD ages of the applicants and the non-applicants for cosmetic surgery were $25.07 \pm 5.74$ and $27.74 \pm 8$ years, respectively. In both groups, more than half of the participants were women and more than $70 \%$ of the applicants and more than $60 \%$ of the non-applicants were single. The educational degree of more than half of the subjects was higher than diploma. About $65 \%$ of the applicants and $42 \%$ of the non-applicants were students. In both groups, $28 \%$ of the participants were earning more than 10 million IRR monthly ( $\$ 1=35000$ IRR). Among different cosmetic surgeries, 79\% were associated with nose surgery (Rhinoplasty), 7\% with suction, $6 \%$ with breast surgery and $8 \%$ with Botox injection.

Body image, self-confidence, and psychological problems

Table 1 presents the mean scores of body image, selfconfidence, and psychological problems of the applicants and the non-applicants for cosmetic surgery. Our data analysis showed that although the mean scores of mental body image and self-confidence were higher in the non-applicants of cosmetic surgery than the applicants, these differences were not statistically significant ( $\mathrm{P}>0.05)$. In addition, no significant difference was seen between the applicants and non-applicants in terms of psychological problems.

Logistic regression was used to study the relationship between all the study variables and being an applicant for cosmetic surgery. Results of the adjusted logistic regression analysis indicate that for each unit increase in selfconfidence, the chance for being an applicant for cosmetic surgery multiplies by 0.92 . Therefore, the increase in self-confidence will reduce the level of applying for cosmetic surgery. Moreover, applying for cosmetic surgery will be 0.88 by increasing the score of psychological problems by one. Therefore, by increase in psychological problems, the demand for cosmetic surgery will reduce. Nevertheless, our data analysis indicated that out of demographic variables, job and income had a significant relationship with applying for cosmetic surgery.

Employed people had a lower chance of being an applicant for cosmetic surgery than students. The chance of cosmetic surgery among individuals with monthly income of 5,000,000 IRR was 13.93 times more than individuals with monthly income lower than 5,000,000 IRR. Regarding the income variable, the great difference between the raw and adjusted values of the odd ratio shows that the relationship between income and applying for cosmetic surgery is affected by confounding factors. Testing several three-variable models indicated that the two variables of age and job had a confounding effect on the relationship between income and applying for cosmetic surgery and after adjusting these effects, the odds ratio increased (Table 2).

\section{Discussion}


Table 1. The comparison of body image, self-esteem, and psychological problems between the applicants and the non-applicants for cosmetic surgery $(n=200)$

\begin{tabular}{|c|c|c|c|c|}
\hline \multirow{2}{*}{ Variable } & \multicolumn{2}{|c|}{ Mean \pm SD } & \multirow{2}{*}{$\begin{array}{c}\text { Mann-Whitney } \\
\text { U Test }\end{array}$} & \multirow{2}{*}{$\mathbf{P}$} \\
\hline & Cosmetic Surgery Applicants & Cosmetic Surgery Non-applicants & & \\
\hline Body image & $126.67 \pm 17.18$ & $130.76 \pm 9.73$ & -0.884 & 0.37 \\
\hline Evaluation of appearance & $15.5 \pm 3.91$ & $16.31 \pm 3.20$ & -1.882 & 0.06 \\
\hline Tendency to appearance & $29.52 \pm 5.96$ & $30.04 \pm 4.90$ & -0.156 & 0.87 \\
\hline Evaluation of fitness & $9.04 \pm 2.16$ & $8.85 \pm 1.94$ & -0.933 & 0.35 \\
\hline Tendency to fitness & $35.59 \pm 6.60$ & $37.62 \pm 6.31$ & -1.726 & 0.084 \\
\hline $\begin{array}{l}\text { Preoccupation with over- } \\
\text { weight or mental weight }\end{array}$ & $5.59 \pm 1.89$ & $5.84 \pm 1.59$ & -0.565 & 0.57 \\
\hline Satisfaction with body areas & $31.43 \pm 8.14$ & $32.1 \pm 5.53$ & -1.032 & 0.30 \\
\hline Self-esteem & $28.91 \pm 6.46$ & $30.04 \pm 5$ & -1.647 & 0.1 \\
\hline Psychological problems & $11.05 \pm 4.18$ & $11.28 \pm 3.5$ & -0.703 & 0.48 \\
\hline
\end{tabular}

Based on the results, the mean score of self-image in non-applicants was higher than applicants of cosmetic surgery but the difference was not statistically significant. In this regard, the study results conducted by other researchers indicate no significant difference between the applicants and non-applicants of cosmetic surgery in terms of stress and body image (Hosseini et al., 2010; (Mohammadpanah et al., 2012). Nevertheless, Zuckerman and Abraham (2008) reported that dissatisfaction with breast and abdomen was the most important causes of cosmetic surgery in America.

Results of another study showed a significant difference between the applicants and non-applicants of cosmetic surgery in terms of self-image, body mass index, general health, and self-concept (Pasha et al., 2008). Thus, although dissatisfaction with self-image can be a motivation for cosmetic surgery, it can partly explain cosmetic surgery and socio-cultural effects should be considered as well. Besides socio-cultural values, the bias of the society on the appearance, comparing individuals based on their appearance and giving value to beauty and complimenting beautiful people, feeling inferior by others (due to the appearances) may make people sensitive to their body images (Saba, 2012).

According to our results, the mean score of self-esteem was not significantly different between the applicants and non-applicants of cosmetic surgery. In addition, the results of adjusted logistic regression indicate that by in- creasing self-esteem, applying for cosmetic surgery will reduce. According to Aliehyaii, Latifi, and Bakkhtiary (2013) low self-confidence and negative self-image were among the main causes of nose surgery.

The results of Sadrosadatzadeh, Farahani, Kiamanesh, and Ramezani (2013) study indicate no significant difference between self-esteem and body image before and after the nose surgery. In contrast, Mackie et al. (2000) reported that cosmetic surgeries are mostly performed because of resolving dissatisfaction with appearance and for increasing self-esteem. According to Zamani and Fazilatpour (2013) cosmetic surgery can contribute to psychological changes such as higher self-esteem, feeling eligible, and improvement of negative self-image.

Regarding such results, low self-esteem is associated with humility, being unvalued and self-inefficiency. Such people would try to cope with their perceived weakness and inefficiency. In other words, they feel that their inefficiency is due to their bad-looking appearances. Therefore, individuals with low self-esteem may choose cosmetic surgery to compensate for their defects (Sadrosadatzadeh et al., 2013). Those with low self-esteem feel that cosmetic surgery is a way to reach the standards of the society for their appearance; however, it seems that such people are not usually satisfied with their body even after the surgery (Tahmasbi, Tahmasbi, \& Yaghmaie, 2014). 
Table 2. The univariate and Multivariate logistic regression model of being a cosmetic surgery applicant

\begin{tabular}{|c|c|c|c|c|c|c|c|}
\hline & \multirow{2}{*}{ Variable } & \multicolumn{3}{|c|}{ Univariate Logistic Regression } & \multicolumn{3}{|c|}{ Multivariate Logistic Regression } \\
\hline & & Odds Ratio & $\begin{array}{c}\text { Confidence } \\
\text { Interval }\end{array}$ & $\mathbf{P}$ & $\begin{array}{l}\text { Odds } \\
\text { Ratio }\end{array}$ & $\begin{array}{l}\text { Confidence } \\
\text { Interval }\end{array}$ & $\mathbf{P}$ \\
\hline & Age & 0.94 & $0.90-0.99$ & 0.01 & 0.94 & $0.88-1.01$ & 0.11 \\
\hline & Body image & 0.98 & $0.96-0.99$ & 0.044 & 0.99 & $0.97-1.02$ & 0.59 \\
\hline & Self esteem & 0.96 & $0.91-1.004$ & 0.07 & 0.92 & $0.85-0.97$ & 0.02 \\
\hline \multicolumn{2}{|c|}{ Psychological problems } & 0.98 & $0.92-1.06$ & 0.67 & 0.88 & $0.79-0.98$ & 0.02 \\
\hline \multirow{2}{*}{ Sex } & Male & 1 & & & 1 & & \\
\hline & Female & 0.51 & $0.28-0.92$ & 0.03 & 0.60 & $0.28-1.3$ & 0.19 \\
\hline \multirow{3}{*}{$\begin{array}{l}\text { Marital } \\
\text { status }\end{array}$} & Married & 1 & & 0.63 & 1 & & 0.53 \\
\hline & Single & 1.34 & & 0.34 & 0.58 & & 0.26 \\
\hline & Divorced & 0.00 & & 1 & 0.00 & & 1 \\
\hline \multirow{3}{*}{ Education } & Low literacy & 1 & & 0.14 & 1 & & 0.12 \\
\hline & Diploma & 0.66 & $0.2-2.18$ & 0.5 & 0.21 & $0.04-1.09$ & 0.06 \\
\hline & Higher than Diploma & 1.35 & $0.46-3.92$ & 0.58 & 0.43 & $0.09-2.12$ & 0.30 \\
\hline \multirow{4}{*}{ Occupation } & Student & 1 & & 0.005 & 1 & & 0.00 \\
\hline & Self-employed & 0.36 & $0.17-0.8$ & 0.012 & 0.08 & $0.02-0.31$ & 0.00 \\
\hline & Employee & 0.25 & $0.1-0.61$ & 0.002 & 0.05 & $0.01-0.2$ & 0.00 \\
\hline & Unemployed & 0.65 & $0.28-1.49$ & 0.31 & 0.32 & $0.08-1.25$ & 0.1 \\
\hline \multirow{3}{*}{$\begin{array}{l}\text { Monthly } \\
\text { income }\end{array}$} & $<5$ million IRR & 1 & & 0.002 & 1 & $4.85-4.02$ & 0.00 \\
\hline & 5 million to 10 million IRR & 3.44 & $1.72-6.89$ & 0.000 & 13.93 & $4.32-44.92$ & 0.00 \\
\hline & $>10$ million IRR & 1.68 & $0.84-3.33$ & 0.14 & 13.93 & & 0.00 \\
\hline
\end{tabular}

In addition, the results related to the psychological problems indicate no significant difference between the applicants and non-applicants in terms of psychological problems. Contrary to our findings, Khanjani et al. (2012), reported a significant difference between the applicants and non-applicants of cosmetic surgery regarding nine dimensions of mental disorders except for paranoid thoughts and psychosis.

Harris and Moss in 2009 found out that before cosmetic surgery, the level of anxiety and depression of appli- cants of surgery was 7.4 and 7.6, respectively compared to non-applicants (Moss \& Harris, 2009). Such discrepancy may be due to the cultural or methodological factors such as research instruments and selected sample. Moreover, the results indicate that job and income have a significant relationship with applying for cosmetic surgery. Individuals who have jobs had a lower chance to apply for cosmetic surgery than students.

Ching, Thoma, McCabe and Antony (2003) in their longitudinal study reported a relationship between at- 
traction and income level even by controlling variables such as age, the level of education, marital status, number of employment years and so on.

The results of Babuccu, Latifoglu, Atabay, Oral and Cosan (2003) study indicate that rich people undergo the highest number of surgeries (with income higher than 8000000 IRR). In a study, it was found that one of the factors affecting cosmetic surgery was educational level rather than income, such that the educational level of applicants of cosmetic surgery was higher than the mean educational level of Iranian women and most of the applicants had university degrees (Mohammadpanah et al., 2012). The results of Mirsardoo, Kaldi and Ataee (2011) study reveal a significant relationship between variables of educational level, family income and cosmetic surgery orientation and also between variables of monthly income and cosmetic surgery or orientation surgery. However, the results of the present study indicate that the chance of being an applicant for cosmetic surgery in people with an income level of higher than 5000000 IRR is 13.93 times more than those with an income level of lower than 5000000 IRR.

Why applicants of cosmetic surgery were students or those with university degrees? Possibly, that students want to be more beautiful than other people because of the sexual and environmental attractions at universities (Mohammadpanah et al., 2012). In the end, cosmetic surgery is a paradox that has been stuck between individual satisfaction and social norms as well as between the domination of capitalists and consumerism. On one hand, the role of social norms and pressures should be considered that would persuade individuals to such surgeries. On the other hand, concerning the position of women in society and the growth of individualism, cosmetic surgery serves a different goal.

Undergoing such operations can be interpreted as resistance against social stereotypes and norms. The women undergo such surgeries for acquiring power because beauty is accompanied with power and allows women to use it in a society with unequal profit opportunities. Since the media should have a responsibility to encourage individuals toward a healthy lifestyle, it is suggested that cultural patterns and factors are introduced by multimedia as incentives for correct decision making and preventing blind imitation.

This study had several limitations. First, the study data were collected from one geographical region. Second, we used convenience sampling method to collect the samples. Therefore, the results should be cautiously generalized to other geographical regions. Furthermore, the non-applicant participants were just relatives of the applicants, who simply mentioned their no intention of doing cosmetic surgery. However, they may have other plans that didn't mention.

According to the present results, although the mean scores of self-esteem, body image, and psychological problems were higher in non-applicants of cosmetic surgery, the differences were not statistically important. On the other hand, it seems that self-esteem, body image, and psychological problems are not the only factors which may peruse Iranians to undergo cosmetic surgery. Therefore, it is necessary to design longitudinal studies to assess the causal factors that may lead to choosing cosmetic surgery among the Iranian population with more details.

\section{Ethical Considerations}

\section{Compliance with ethical guidelines}

Kerman University of Medical Sciences approved this project (Ethical code: 56/93/k). After the approval, necessary permissions were taken from the management of Ali-ebne-Abitaleb and Morady hospitals of Rafsanjan City. The researcher informed all participants about the study objectives, the confidentiality, and anonymity of the participants' information, and their right to withdraw from the study at any time. All subjects gave their verbal consent.

\section{Funding}

This research did not receive any specific grant from funding agencies in the public, commercial, or not-forprofit sectors.

\section{Authors contributions}

All authors contributed in preparing this article.

\section{Conflict of interest}

The authors declare no conflict of interest.

\section{Acknowledgements}

The researchers would like to appreciate all the participants and the Research Council of the Kerman University of Medical Sciences who provided facilities for conducting this study. 


\section{References}

Ahmadi, H., \& Poorsharifi, H. (2013). [The role of news source on individuals persuasion with moderation of attitude to news source, gender and self-esteem (Persian)]. Social Cognition, 2(3), 7-18.

Aliehyaii, F., Latifi, A., \& Bakhtiary, M. (2013). An epidemiological study of the reasons for tendency to undergo rhinoplasty in Tehran. Teb va Tazkieh, 22, 9-16.

Babuccu, O., Latifoglu, O., Atabay, K., Oral, N., \& Cosan, B. (2003). Sociological aspects of rhinoplasty. Aesthetic Plastic Surgery, 27(1), 44-9. [DOI:10.1007/s00266-002-1517-9] [PMID]

Baniasadi, H. (2012). Effects of rhinoplasty on women's body image. Journal of Dermatology and Cosmetic, 3(4), 194-201.

Ching, S., Thoma, A., McCabe, R. E., \& Antony, M. M. (2003) Measuring outcomes in aesthetic surgery: A comprehensive review of the literature. Plastic and Reconstructive Surgery, 111(1), 469-82. [DOI:10.1097/01.PRS.0000036041.67101.48] [PMID]

Dowling, N. A., Jackson, A. C., \& Honigman, R. J. (2013). A comparison of the psychological outcomes of cosmetic surgical procedures. Plastic Surgery: An International Journal, 2013(2013), 979486

Farshidfar, Z., Dastjerdi, R., \& Shahabizadeh, F. (2013). Acceptance of cosmetic surgery: body image, self esteem and conformity. Procedia-Social and Behavioral Sciences, 84, 238-42. [DOI:10.1016/j.sbspro.2013.06.542]

Frederick, D. A., Lever, J., \& Peplau, L. A. (2007). Interest in cosmetic surgery and body image: Views of men and women across the lifespan. Plastic and Reconstructive Surgery, 120(5), 1407-15. [DOI:10.1097/01.prs.0000279375.26157.64] [PMID]

Hosseini, S. E., Ghasemi, N., Molayi Gonbadi, G., \& Rezayi, L (2010). [Comparison of the level of stress and body image among individuals aged 20-30 seeking and not seeking cosmetic surgeries in Ahvaz province (Persian)]. Journal of Modern Industrial/Organization Psychology, 1(3), 75-84.

Jomeen, J., \& Martin, C. R. (2005). Self-esteem and mental health during early pregnancy. Clinical Effectiveness in Nursing, 9(1), 92-95. [DOI:10.1016/j.cein.2004.09.001]

Khanjani, Z., Babapour, J., \& Saba, G. (2012). Investigating mental status and body image in cosmetic surgery applicants in comparison with non-applicants. Journal of Shahid Sadoughi University of Medical Sciences, 20(2), 237-48.

Kkeli, N., \& Argyrides, M. (2013). Appearance Schemas Inventory Revised: Psychometric Properties of the Greek Version in a Female Sample. North American Journal of Psychology, 15(3), 577-88.

Klassen, A., Jenkinson, C., Fitzpatrick, R., \& Goodacre, T. (1996). Patients' health related quality of life before and after aesthetic surgery. British Journal of Plastic Surgery, 49(7), 433-8. [DOI:10.1016/S0007-1226(96)90025-9]

Kvalevaag, A. L., Ramchandani, P. G., Hove, O., Assmus, J., Eberhard-Gran, M., \& Biringer, E. (2013). Paternal mental health and socioemotional and behavioral development in their children. Pediatrics, 131(2), e463-e9. [DOI:10.1542/ peds.2012-0804]
Mackie, D. M., Devos, T., \& Smith, E. R. (2000). Intergroup emotions: Explaining offensive action tendencies in an intergroup context. Journal of Personality and Social Psychology, 79(4), 602.

Mirsardoo, T., Kaldi, A., \& Ataee, B. (2011). [Relationship between socio-cultural factors and women's tendency to beauty care among women in Karaj (Persian)]. Woman and Family Studie, 3(10), 145-64.

Mohammadpanah Ardakan, A., \& Yousefi, R. (2011). [Assessment of beliefs about appearance and inferiority feeling in cosmetic surgery candidates (Persian)]. Journal of dermatology and cosmetic, 2(2), 85-97.

Mohammadpanah, A, Yaghoobi, H, \& Yusefi, R. (2012). [Personality traits and defense mechanisms in patients seeking for cosmetic surgery (Persian)]. Dermatology and Cosmetic, $3(2), 72-82$

Moss, T. P., \& Harris, D. L. (2009). Psychological change after aesthetic plastic surgery: A prospective controlled outcome study. Psychology, Health \& Medicine, 14(5), 567-72. [DOI:10.1080/13548500903112374] [PMID]

Mousavizadeh, S. M., Niazi Shahraki, F., Kalantar Hormozi, A., Fadaei Naeini, A. R., \& Nasri Lari, M., (2010). [Assessing tendencies and motivations of female volunteers for cosmetic surgery (Persian)]. Pajoohandeh Journal, 14(6), 318-23.

Pasha, G. R., Naaderi, F., \& Akbari, S. (2008). [Comparison of body image, body mass index, general health, and self concept between people experienced cosmetic surgery, applicants for cosmetic surgery and normal sample of Behbahan (Persian)]. New Findings in Psychology, 2(7), 61-80.

Piyavhatkul, N., Aroonpongpaisal, S., Patjanasoontorn, N., Rongbutsri, S., Maneeganondh, S., \& Pimpanit, W. (2011). Validity and reliability of the Rosenberg Self-Esteem Scale-Thai version as compared to the Self-Esteem Visual Analog Scale. Journal of the Medical Association of Thailand=Chotmaihet thangphaet, 94(7), 857-862.

Riggs, L. E. (2012). The globalization of cosmetic surgery: Examin ing BRIC and beyond [MA. thesis]. San Francisco: University of San Francisco.

Saba, G. (2012). [Comparison of psychopathology in people seeking cosmetic surgery with controls (Persian)]. Pajoohandeh Journal, 17(1), 26-31.

Sadrosadatzadeh, M., Farahani, M., Kiamanesh, A., \& Ramezani, V. (2013). [Qualification of self-esteem and body image before and after cosmetic surgery on girls (Persian)]. Journal of Research in Psychological Health, 7(1), 40-8.

Sarwer, D. B., Wadden, T. A., Moore, R. H., Eisenberg, M. H. Raper, S. E., \& Williams, N. N. (2010). Changes in quality of life and body image after gastric bypass surgery. Surgery for Obesity and Related Diseases, 6(6), 608-14. [DOI:10.1016/j. soard.2010.07.015] [PMID] [PMCID]

Tahmasbi, S., Tahmasbi, Z., \& Yaghmaie, F. (2014). [Factors related to cosmetic surgery based on theory of reasoned action in shahrekord students (Persian)]. Journal of Holistic Nursing And Midwifery, 24(4), 53-61.

Tousi, P., Barikbin, B., Arbabi, M., \& Saati, S. (2007). Evaluation of 116 patients treated with botulimum toxin referred to private dermatologic clinics in Tehran (Persian)]. Iranian Journal of Dermatology, 10(2), 125-9. 
Von Soest, T., Kvalem, I., Roald, H., \& Skolleborg, K. (2009). The effects of cosmetic surgery on body image, self-esteem, and psychological problems. Journal of Plastic, Reconstructive $\mathcal{E}$ Aesthetic Surgery, 62(10), 1238-44. [DOI:10.1016/j. bjps.2007.12.093] [PMID]

Zamani, S., \& Fazilatpour, M. (2013). [The effects of cosmetic surgery on patients' self-esteem and negative image of themselves (Persian)]. Journal of Kerman University of Medical Sciences, 20(5), 492-504.

Zuckerman, D., \& Abraham, A. (2008). Teenagers and cosmetic surgery: Focus on breast augmentation and liposuction. Journal of Adolescent Health, 43(4), 318-24. [DOI:10.1016/j.jadohealth.2008.04.018] [PMID] 
This Page Intentionally Left Blank 